\title{
Polypharmacy and Drug-Drug Interactions in Older and Younger People Living with HIV: The POPPY Study
}

M. O Halloran ${ }^{1,2}$, C. Boyle ${ }^{1}$, B. Kehoe ${ }^{1}$, E. Bagkeris ${ }^{3}$, P. Mallon ${ }^{4}$, Frank A. Post ${ }^{5}$, J. Vera ${ }^{6}$, lan Williams ${ }^{7}$ Jane Anderson $^{8}$, A. Winston ${ }^{9}$ M. Sachikonye ${ }^{10}$, C. Sabin ${ }^{3}$, M. Boffito ${ }^{9,11}$.

1. Mater Misericordiae University Hospital, Pharmacy Department, Dublin, Ireland

2. School of Pharmacy, Trinity College Dublin, Ireland

3. University College London, London, United Kingdom

4. University College Dublin, Ireland

5. King's College Hospital NHS Foundation Trust, London, United Kingdom

6. Brighton and Sussex University Hospitals NHS Trust, Brighton, United Kingdom

7. NHS Mortimer Market Centre, London, United Kingdom

8. Homerton University Hospital, London, United Kingdom

9. Imperial College, London, United Kingdom

10. iBase, London, United Kingdom

11. St Stephen's AIDS Trust, Chelsea and Westminster Hospital, London, United Kingdom

Keywords: Polypharmacy, Potential Drug-Drug Interactions, HIV, Aging

Issue Section: Original Research

Corresponding author: $\mathrm{M} \mathrm{O}$ Halloran

Mater Misericordiae University Hospital, Pharmacy Department, Dublin, Ireland.

Tel. 0035318032042

Email. mohalloran@mater.ie

Word Count-Abstract: 220

Word Count-Main Text: 2874 


\section{Abstract}

Objectives: Polypharmacy (use of $\geq 5$ medications) increases the risk of drug-drug interactions and can lead to negative health outcomes. This study aimed to review the medications of people living with HIV (PLWH) and HIV negative controls in the POPPY study and evaluate the frequency of polypharmacy and potential drug-drug interactions (PDDI).

Methods: Potential drug-drug interactions between non-antiretroviral (ARV) drugs were analysed using the Lexicomp ${ }^{\circledast}$ database, and PDDI between non-ARV and ARV drugs using the Liverpool drug interaction database (www.hiv-druginteractions.org). Between-group differences were assessed using Chi-squared, Mann-Whitney U and Kruskal Wallis tests.

Results: This analysis included 698 PLWH $\geq 50$ years, 374 PLWH $<50$ years and 304 HIV-negative controls $\geq 50$ years. The prevalence of polypharmacy was $65.8 \%$ in older PLWH, $48.1 \%$ in younger PLWH, and $13.2 \%$ in the HIV negative group. When ARVs were excluded $29.8 \%$ of older PLWH and $14.2 \%$ of younger PLWH had polypharmacy. The prevalence of $\geq 1$ PDDI involving non-ARV drugs was 36.1\%, 20.3\% and $16.4 \%$ respectively in older PLWH, younger PLWH and HIV negative controls. In PLWH the prevalence of $\geq 1$ PDDI involving ARV and non-ARV drugs was $57.3 \%$ in older PLWH and $32.4 \%$ in younger PLWH.

Conclusion: Polypharmacy and PDDI involving non-ARV/ARV drugs and non-ARV/non-ARV drugs were common among older PLWH, highlighting the need for increased awareness and additional research on all types of PDDI. 


\section{Introduction}

With the advancement of antiretroviral (ARV) therapy, people living with HIV (PLWH) are living longer. ${ }^{1}$ The clinical focus has increasingly shifted from the management of HIV related complications to managing comorbidities, ${ }^{2}$ polypharmacy, and drug-drug interactions that may arise from medication use. There are many descriptions of the term polypharmacy, but it has commonly been defined in the literature as the regular use of five or more medications., ${ }^{3,4}$ Polypharmacy among PLWH specifically has been identified as a clinical concern. ${ }^{5,6} \mathrm{~A}$ correlation between the number of non-ARV drugs and adverse health outcomes has been demonstrated in both older PLWH and uninfected older individuals. ${ }^{7}$ Although polypharmacy is often unavoidable in older patients, including PLWH, the potential negative consequences of multi-medication intake must be carefully considered. These include decreased adherence to treatments ${ }^{8}$, increased risk of hospitalisation, increased risk of adverse drug reactions or additive drug toxicities $9,10,11,12$, increased costs ${ }^{13}$, pill burden ${ }^{14}$ and increased risk of geriatric syndrome, which is a collection of conditions traditionally associated with older age, including falls, delirium, incontinence and decreased nutrition status. ${ }^{15,16} \mathrm{~A}$ major concern about polypharmacy is the risk of clinically significant potential drug-drug interactions (PDDI). ${ }^{17,18}$

PDDI are a well-recognised concern in PLWH ${ }^{19,20,21}$ as ARVs can be inhibitors (e.g. ritonavir, cobicistat), inducers (e.g. efavirenz, nevirapine) or substrates (e.g. rilpivirine, maraviroc and the newer agents bictegravir and doravirine) of the cytochrome P450 (CYP450) system isoenzymes. ${ }^{22,23}$ Drugs may alter the function of enzymes (eg UDP glucuronosyltransferases (UGTs)), transporters (eg P-glycoprotein (P-gp), organic anion/cation transporters etc. Interactions involving ARVs may also occur with drugs that alter gastric $\mathrm{pH}$ (e.g proton pump inhibitors), and drugs that act as chelating agents (eg calcium and magnesium containing compounds) may affect ARV absorption. ${ }^{23,24}$ The consequences of such PDDI may be serious toxicities or a reduction in ARV drug concentrations that leads to virological failure and development of resistance to ARV therapy. ${ }^{25}$

Although traditionally the focus has been on ARV/non-ARV PDDI, PDDI involving non-ARVs in PLWH are also of emerging concern, in view of the high levels of non-ARV polypharmacy encountered in this population. Our aim was to analyse the prevalence of PDDI between both ARV/non-ARVs and nonARVs/non-ARVs in three groups of people: $\mathrm{PLWH} \geq 50$ years of age, younger PLWH, and people without $H I V \geq 50$ years. 


\section{Methods}

The Pharmacokinetic and Clinical Observations in People Over 50 (POPPY) study is a multicentre, prospective, observational study, with data collection taking place over a three-year period from 20132016. ${ }^{26}$ Data from 1376 participants were collected: PLWH $\geq 50$ years $(n=698)$, PLWH 20-49 years ( $n$ $=374)$, and HIV negative individuals $\geq 50$ years $(n=304)$. The study comprises a cohort that represents the overall clinic population i.e. did not over-represent those with more complex medical needs who either attended clinic more frequently or those who were more regular participants in research studies. Where possible, HIV-negative participants were selected from similar underlying populations. Participants were recruited across eight clinical centres in the UK and Ireland. Ethical, regulatory and informed consent, if indicated, was obtained from each study site.

\section{Polypharmacy assessment}

Information on medication usage was obtained at study entry by trained study staff; additional information on ARV usage among PLWH was obtained through linkage with the UK Collaborative HIV Cohort (UK CHIC) study. ${ }^{27}$ Analyses were performed on data obtained at the baseline visit. For the purpose of this analysis the following medications were included: ARVs, non-ARV prescribed drugs, over the counter medications, dietary and vitamin supplements and homeopathic medications (recreational drugs were not included in the analysis). For both ARV and non-ARV combinations, individual components were counted and analysed separately e.g. Co-codamol ${ }^{\circledR}$ was inputted as paracetamol and codeine. Certain combinations, whose individual components could not possibly be determined e.g. "Multivitamin" were counted as one medicine. Medications were recorded and classified based on the World Health Organization (WHO) Anatomical Therapeutic Chemical Classification (ATC) system. Certain medicines were reclassified for example aspirin was only included in the blood (anti-platelet) category of medications. Polypharmacy was defined as five or more medications in line with other published studies. 3,28,29

\section{Potential drug-drug interactions}

For PLWH, the University of Liverpool HIV drug interactions database (www.hiv-druginteractions.org) was used to determine interactions between ARV and non-ARV medications. The interaction checker classifies specific ARV and non-ARV combinations as being contraindicated (colour code red), potentially clinically significant that are likely to require additional monitoring, alteration of drug dosage or timing of administration (colour code amber) or having no interaction (colour code green). ${ }^{30}$ The option to check interactions between ARVs was not used, as it was assumed these interactions were intentional e.g darunavir and ritonavir, where ritonavir is used a pharmacokinetic enhancer. 
For both HIV positive and negative participants, the Lexicomp ${ }^{\circledR}$ database was used to check interactions between non-ARV/non-ARV medications. Lexicomp ${ }^{\circledR}$ classifies interactions as class $A$ (no known interaction), B (no action needed), C (monitor therapy), D (consider therapy modification), and $\mathrm{X}$ (avoid combination). ${ }^{31}$ Examples in class $\mathrm{X}$ include co-administration of opioids with other opioids or co-administration of domperidone with quinolones. In this study the interactions categorised in class $D$ were sub-divided into those requiring therapy modification and those that could be managed by separating administration times e.g levothyroxine and calcium. All interactions were included, except interactions between two drugs that were duplicated due to different mechanisms of interaction e.g two drugs which may both lower seizure threshold and prolong QTc interval. These combinations were only included once with the highest severity assigned to the interaction.

\section{Statistical Analysis}

Proportions, frequencies, means and ranges were used for the descriptive analyses. Patient characteristics between groups were compared using Pearson's chi-square tests for categorical variables and non-parametric Kruskal-Wallis tests for continuous variables. Multivariable logistic regression models were used to assess the association of PDDI between non-ARV and non-ARV drugs and PDDI between ARV and non-ARV drugs with HIV group after adjusting for gender and race and current combination antiretroviral therapy (CART). Statistical analysis was performed using Microsoft Exce $^{\circledR}$ and Stata 15 (StataCorp. 2017. Stata Statistical Software: Release 15. College Station, TX: StataCorp LLC).

\section{Results}

The characteristics of the study population are illustrated in Table 1. Reflecting the characteristics of the older HIV-positive population in the UK and Ireland, the older group of PLWH were predominantly male, men who have sex with men (MSM) and of white ethnicity; the younger group of PLWH and older HIV-negative controls were broadly similar in terms of these demographic characteristics. 


\section{Medication Characteristics}

\section{Conventional Medications}

In PLWH $\geq 50$ years ATC class $C$, the cardiovascular system, was the most common therapeutic class accounting for $19.7 \%$ ( $n=479$ ) of the 2426 co-medications in this group. ATC class N, drugs used to treat the nervous system, accounted for $16.8 \%(n=408)$ of all co-medications. ATC Class J, antiinfectives for systemic use, accounted for $10.8 \%(n=261)$ and ATC Class A, drugs for the Alimentary Tract and Metabolism made up $8.9 \%(n=215)$ of all co-medications.

In PLWH $<50$ years, ATC class $\mathrm{N}$ was the most common therapeutic class, accounting for $20.1 \%$ $(n=146)$ of the 726 co-medications. ATC class J made up $10.2 \%(n=74)$ of all co-medications, and ATC Class $R$, respiratory medicines, accounted for $9.4 \%(n=68)$.

In the HIV-negative group $\geq 50$ years ATC class $C$ was the most common therapeutic class, accounting for $17.9 \%(n=107)$ of the 598 co-medications. ATC Class N made up $8.5 \%(n=51)$ of all comedications and ATC Class A accounted for 7.9\% $(n=47)$.

\section{Non-Conventional Medications}

A large proportion of all three groups were taking non-conventional medications (e.g vitamins, minerals, herbal and homeopathic remedies, dietary supplements). Among PLWH $\geq 50$ years 228 (32.7\%) were taking at least one non-conventional medication, compared to 91 (29.9\%) of those in the HIV-negative group $\geq 50$ years and 127 (34\%) of PLWH $<50$ years.

\section{Polypharmacy}

The numbers of people with polypharmacy in each of the three groups is illustrated in Table 2.

In PLWH $\geq 50$ years the group were taking a median of six medications including ARVs (Interquartile Range (IQR) 4,9), PLWH $<50$ years were taking a median of four medications including ARVs (IQR $3,6)$ and the HIV-negative group $\geq 50$ years were taking a median of one medication $(I Q R 0,3)(p=$ $0.001)$.

PLWH $\geq 50$ years had more polypharmacy than the other two groups: 459/698 (65.8\%) older PLWH had polypharmacy compared to 180/374 (48.1\%) younger PLWH and 40/304 (13.2\%) HIV-negative people $\geq 50$ years $(p=0.001)$.

When ARVs were excluded from the analysis in the HIV positive groups, 208/698 (29.8\%) of older PLWH had polypharmacy. This is considerably more than the HIV negative group $\geq 50$ years, of whom 
13.2\% had polypharmacy. In younger PLWH 53/374 (14.2\%) had polypharmacy when ARVs were excluded.

\section{Potential drug-drug interactions}

Table 2 reports the frequency of PDDI in the studied population. A significantly higher proportion of older PLWH had at least one PDDI involving both an ARV/non-ARV than younger PLWH, and a nonARV/non-ARV than younger PLWH and the HIV negative group $\geq 50$ years.

\section{Potential drug-drug interactions between non-antiretrovirals and antiretrovirals}

Of the 913 total PDDI between non-ARV and ARV medications identified in older PLWH, 25 were classed as contraindicated interactions and 888 were classed as potential interactions. Clopidogrel $(n=11)$ proton pump inhibitors $(n=5)$ and inhaled corticosteroids $(n=4)$ were the most frequently observed contraindicated co-medications in this group. Among younger PLWH, 201 total PDDI were measured with four being classed as contraindicated interactions and 197 classed as potential interactions. Three contraindicated interactions in this group involved inhaled corticosteroids and one involved clopidogrel. The ARV medications implicated in contraindicated interactions were all in the protease inhibitor class. White ethnicity and belonging to the PLWH aged $\geq 50$ years group increased the odds of PDDI between ARV and non-ARV drugs compared to PLWH aged $<50$ years (odds ratio $(\mathrm{OR})=2.00$, [95\% confidence interval $(\mathrm{Cl}) 1.26,3.18], \mathrm{p}=0.003$ and $\mathrm{OR}=2.65[95 \% \mathrm{Cl} 2.02,3.47], \mathrm{p}<$ 0.001 respectively after adjusting for gender and current ARV regimen). Moreover, the POPPY participants on a Non-Nucleoside Reverse Transcriptase Inhibitor (NNRTI) without a Protease Inhibitor (PI), any Integrase Inhibitor (II) without a PI/NNRTI and participants on other ARV regimens compared to those on PI-containing regimen were $47 \%, 54 \%$ and $90 \%$ less likely to have a PDDI between ARV and non-ARV drugs $(\mathrm{OR}=0.53,[95 \% \mathrm{Cl} 0.41,0.69], \mathrm{p}<0.001, \mathrm{OR}=0.46,[95 \% \mathrm{Cl} 0.28,0.73, \mathrm{p}=0.001$ and $\mathrm{OR}=0.10,[95 \% \mathrm{Cl} 0.04,0.26], \mathrm{p}<0.001$ respectively) (Table 5).

\section{Potential drug-drug interactions between non-antiretrovirals and non-antiretrovirals}

The odds of PDDI between non-ARV and non-ARV drugs was more than 3 times higher in PLWH aged $\geq 50$ years compared to HIV-negative controls after adjusting for gender and race (odds ratio 3.08 $[2.16,4.42], p<0.001$ ) (Table 5).

As seen in Table 4 older PLWH had more interactions that were classed as "Do not co-administer" than the younger PLWH or older HIV negative controls $(2.6 \%(n=31)$ of all non-ARV drug interactions versus $0.7 \%(n=1)$ and $0.4 \%(n=1)$ respectively. 


\section{Discussion}

In this analysis of polypharmacy from the POPPY study, we showed that among PLWH $\geq 50$ years, $74.5 \%$ were receiving at least one co-medication (i.e. medication other than ARVs), compared to $62 \%$ of PLWH $<50$ years. Furthermore, we showed that polypharmacy was more common among older PLWH than HIV negative controls or younger PLWH, and that they were more at risk of a PDDI: i) involving non-ARV/non-ARV drugs than HIV-negative controls, and ii) involving non-ARV/ARV drugs than younger PLWH. This shows the importance of considering co-medications when assessing appropriate ARV treatment choices for this group. While this has likely occurred because of the increasing age of PLWH and subsequently the increased prevalence of diseases of older age in this group, it must also be considered that older PLWH may attend more individual specialists to deal with co-morbidities. While this practice may make it difficult to rationalise patient's medication regimens, it should not preclude attempts to do so.

A large scale Irish study of older people over 50 years found that $19 \%$ of participants had polypharmacy ${ }^{32}$, the results from our own study show significantly higher rates of polypharmacy in PLWH. It is not surprising that all PLWH had significantly more polypharmacy rates compared to the HIV negative group. Most of the studied PLWH were on ARV therapy, $98.7 \%$ of older PLWH and $94.9 \%$ of younger PLWH. Most ARV therapy comprises of at least three medications, and these were counted separately for the purposes of this study. Consequently, many PLWH only need to have an additional two medications to meet the criteria for polypharmacy as we have defined it in this study. However when ARVs were excluded $29.8 \%$ of older PLWH had polypharmacy. This finding suggests older PLWH are more likely to have a greater medication burden, independent of their ARV therapy. The reasons for this are multifactorial and could include the higher frequency of multimorbidity which seems to occur earlier in life in PLWH ${ }^{33}$ and the involvement of various healthcare providers that prescribe different medications. There also may be a reluctance on the part of prescribers to reduce medication that has been started by prescribers from other specialities.

There was a relatively small number of overall contraindicated interactions $(2.7 \%(n=25)$ in older PLWH and $2 \%(n=4)$ in younger PLWH) between ARV and non-ARV medications. In older PLWH 3.6\% (25/698) of people had a contraindicated ARV/non-ARV combination, and in younger PLWH 1.1\% (4/374) of the group had a contraindicated combination. This is of a similar prevalence to that in the Swiss cohort study $(2 \%)^{19}$, and an Australian cohort study $(3 \%)^{34}$ which suggests good awareness of contraindicated combinations. Clopidogrel, proton pump inhibitors and corticosteroids were implicated in the majority of contraindicated interactions between non-ARV and ARV drugs, and it is clear that extra care should be taken to avoid these medications being co-prescribed along with protease inhibitors. 
Furthermore, our study identified many PDDI involving non-ARV/non-ARV medications. Although these interactions varied in terms of severity, it is important to underline that some of the interactions described may be associated with clinically significant events. Due to the higher rates of comorbidities, PLWH may be more vulnerable than the general population to the effects of complications associated with PDDI such as treatment failure or drug toxicity. The high prevalence of PDDI outside the use of ARVs in ageing PLWH suggests the need for better integrated, multidisciplinary care with regular review of co-medications.

Having identified the areas in which these interactions occur and the recommended actions that should be taken, pre-emptive measures can be put in place to minimise the risk of a person experiencing an adverse outcome as the result of a DDI. Many studies examining polypharmacy only examine conventional medications, and do not include herbal medications and supplements which may result in underestimating polypharmacy. This study has shown that non-conventional medications make up a significant proportion of all co-medications, in all three populations in the study, and by including non-conventional medications a more accurate description of polypharmacy was obtained.

There were limitations associated with our study. One study limitation was the lack of data on dosing information on most medications. This means that some interactions may have been overestimated as the interaction may only apply where the medication is taken above a certain dose e.g. aspirin has a different interaction profile depending if it used as an anti-platelet or an analgesic. Furthermore, some medications may have been started and stopped at various time points over the course of the study, as the medication list was collected at study entry and not updated after this. The medication list obtained was a self-reported list. Prompts were given to participants to provide as accurate a list as possible, however it is possible that medication use may have been underreported, especially herbal and other non-conventional medications. Although many centres have excellent communication between healthcare professionals, and between primary and secondary care, the lack of access to a complete prescription list that can be accessed by all healthcare professionals remains a limitation. Lexicomp ${ }^{\circledR}$ was the only interaction checker used in this study for non-ARV interactions. It is a sensitive interaction checker, and many of the interactions flagged may not be clinically relevant in practice, especially those classified as no action needed. Pill burden was not determined as data on specific formulations was not specifically sought, and where combination product names were provided these medications were separated for the purposes of this study. 
In conclusion, the findings from our study suggest that older PLWH are at higher risk for polypharmacy and PDDI than younger PLWH and older HIV negative people. Importantly, even independently of ARV therapy, polypharmacy and PDDI are more common in older PLWH than older HIV negative adults.

The findings above emphasise how imperative it is to focus on polypharmacy and PDDI in older PLWH who are taking multiple medications. There is a big focus on rationalising medications in the older population ${ }^{35}$ and PLWH should not be exempt from this process. Older PLWH may benefit from input from specialists in geriatrics and pharmacy to ensure that all medications are rationalised and deprescribed if appropriate. Polypharmacy and PDDI in the HIV population are likely to increase in importance as the age of this cohort continues to rise. Priorities for the future should include focus on non-ARV interactions in older people with HIV, and rationalising medication use to ensure appropriate polypharmacy which would minimise the risk of PDDI. 


\section{Acknowledgments}

We thank all participants in the study.

POPPY Management Team: Daphne Babalis, Marta Boffito, Laura Burgess, Paddy Mallon, Frank Post, Caroline Sabin, Memory Sachikonye, Alan Winston.

POPPY Scientific Steering Committee: Jane Anderson, David Asboe, Marta Boffito, Lucy Garvey, Paddy Mallon, Frank Post, Anton Pozniak, Caroline Sabin, Memory Sachikonye, Jaime Vera, Ian Williams, Alan Winston.

POPPY sites: Elton John Centre, Brighton and Sussex University Hospital (Amanda Clarke, Jaime Vera, Andrew Bexley, Celia Richardson, Sarah Kirk, Rebecca Gleig); St Stephen's Centre, Chelsea and Westminster Hospital (Marta Boffito, David Asboe, Anton Pozniak, Margherita Bracchi, Nicole Pagani, Maddalena Cerrone, Daniel Bradshaw, Francesca Ferretti, Chris Higgs, Elisha Seah, Stephen Fletcher, Michelle Anthonipillai, Ashley Moyes, Katie Deats, Irtiza Syed, Clive Matthews, Peter Fernando, Chido Chiwome, Shane Hardwick); Homerton Sexual Health Services, Homerton University Hospital (Jane Anderson, Sifiso Mguni, Rebecca Clark, Rhiannon Nevin-Dolan, Sambasivarao Pelluri); Caldecot Centre, King's College Hospital (Frank Post, Lucy Campbell, Selin Yurdakul, Sara Okumu, Louise Pollard, Beatriz Santana-Suarez); HIV Molecular Research Group, School of Medicine, University College Dublin (Paddy Mallon, Alan Macken, Bijan Ghavani-Kia, Joanne Maher, Maria Byrne, Ailbhe Flaherty, Sumesh Babu); Research Department of Infection and Population Health, University College London (Ian Williams, Damilola Otiko, Laura Phillips, Rosanna Laverick, Michelle Beynon, Anna-Lena Salz, Abigail Severn); St Mary's Hospital London, Imperial College Healthcare NHS Trust (Alan Winston, Lucy Garvey, Jonathan Underwood, Lavender Tembo, Matthew Stott, Linda McDonald, Felix Dransfield); Imperial Clinical Trials Unit, Imperial College London (Andrew Whitehouse, Laura Burgess, Daphne Babalis); Ian Charleson Day Centre, Royal Free Hospital 
(Margaret Johnson, Nnenna Ngwu, Nargis Hemat, Martin Jones, Anne Carroll, Sabine Kinloch, Mike Youle, Sara Madge);

POPPY methodology, statistics and analysis group: Caroline Sabin, Davide De Francesco, Emmanouil Bagkeris.

Funding: This work is supported by investigator initiated grants from Bristol-Myers Squibb, Gilead Sciences, Janssen-Cilag, Merck Sharp and Dohme, and ViiV Healthcare.

\section{Other acknowledgements}

We acknowledge the use of the NIHR/Wellcome Trust Clinical Research Facility at King's College Hospital.

\section{Trinity College Dublin}

Professor Martin Henman and Niamh McMahon

The research is supported by the National Institute for Health Research (NIHR) Biomedical Research Centre based at Imperial College Healthcare NHS Trust and Imperial College London and by a NIHR Senior Investigator Award to Professor C Sabin. The views expressed are those of the author(s) and not necessarily those of the NHS, the NIHR or the department of Health.

All the POPPY clinical sites in the UK are grateful for NIHR Clinical Research Network (CRN) support.

\section{Conflicts of Interest}

$\mathrm{MOH}$ No conflicts

C Boyle No conflicts

BK No conflicts

EB No conflicts 
PM received funding for Advisory Boards, speaker panels, preparation of educational materials and/or research grants to his institution from Gilead Sciences, ViiV Healthcare, BMS, MSD, Abbvie and Janssen-Cilag

DB No conflicts

JV No conflicts

AW received honoraria or research grants from VliV Healthcare, Gilead Sciences, BMS, Merck and Co. and Janssen

CS received funding from Gilead Sciences, ViiV Healthcare and Janssen-Cilag for the membership of Data Safety and Monitoring Boards, Advisory Boards, Speaker Panels and for the preparation of educational materials

MB has received travel and research grants from and has been speaker/advisor for Janssen, Roche, ViiV, Bristol-Myers Squibb, Merck Sharp \& Dohme, Gilead, Mylan, Cipla, Teva

FAP has received research grants from Gilead Sciences and ViiV Healthcare, and has been a speaker or advisor for Gilead Sciences, ViiV Healthcare, MSD and Janssen 
Legends to Tables and Figures

Table 1: Characteristics of the study population

Table 2: Numbers of medications and interactions in the three groups

Table 3: Non-ARV drugs involved in interactions with ARVs

Table 4: Non-ARV drug interactions

Table 5: Association of PDDI between non-ARV and non-ARV drugs and PDDI between ARV and nonARV drugs with HIV group, gender, race and ARV therapy 


\section{References}

1. May MT, Gompels M, Delpech V, Porter K, Orkin C, Kegg S, et al. Impact on life expectancy of HIV-1 positive individuals of CD4+ cell count and viral load response to antiretroviral therapy. AIDS. 2014 May 15;28(8):1193-202.

2. Hasse B, Ledergerber B, Furrer H, Battegay M, Hirschel B, Cavassini M, et al. Morbidity and Aging in HIV-Infected Persons: The Swiss HIV Cohort Study. Clin Infect Dis. 2011 Dec 1;53(11):1130-9.

3. O'Dwyer M, Peklar J, McCallion P, McCarron M, Henman MC. Factors associated with polypharmacy and excessive polypharmacy in older people with intellectual disability differ from the general population: a cross-sectional observational nationwide study. BMJ Open. 2016 Apr 4;6(4):e010505.

4. Fallis A. Polypharmacy in elders over 50 in Ireland: opportunities for cost saving and improved health care. Vol. 53, Journal of Chemical Information and Modeling. 2013. 1689-1699 p.

5. Núñez-Núñez M, Castañeda-Macías I, Sandoval-Fernández Del Castillo S. Potential interactions in a cohort of elderly hiv-positive patients. Farm Hosp. 2018;42(4):163-7.

6. Ranzani A, Oreni L, Agrò M, van den Bogaart L, Milazzo L, Giacomelli A, et al. Burden of Exposure to Potential Interactions Between Antiretroviral and Non-Antiretroviral Medications in a Population of HIV-Positive Patients Aged 50 Years or Older. JAIDS J Acquir Immune Defic Syndr. 2018 Jun;78(2):193-201.

7. Justice AC, Gordon KS, Skanderson M, Edelman EJ, Akgün KM, Gibert CL, et al. Nonantiretroviral polypharmacy and adverse health outcomes among HIV-infected and uninfected individuals. AIDS. 2018 Mar;32(6):739-49.

8. Maher RL, Hanlon J, Hajjar ER. Clinical consequences of polypharmacy in elderly. Expert Opin Drug Saf. 2014 Jan;13(1):57-65.

9. Shah BM, Hajjar ER, Blue R, al. et. Polypharmacy, adverse drug reactions, and geriatric syndromes. Clin Geriatr Med. 2012 May 1;28(2):173-86.

10. Greene M, Steinman MA, McNicholl IR, Valcour V. Polypharmacy, drug-drug interactions, and potentially inappropriate medications in older adults with human immunodeficiency virus infection. J Am Geriatr Soc. 2014;62(3):447-53.

11. Edwards IR, Aronson JK. Adverse drug reactions: definitions, diagnosis, and management. Lancet. 2000 Oct;356(9237):1255-9.

12. Gurwitz JH, Field TS, Harrold LR, Rothschild J, Debellis K, Seger AC, et al. Incidence and preventability of adverse drug events among older persons in the ambulatory setting. JAMA. 2003 Mar 5;289(9):1107-16.

13. Cahir C, Fahey T, Teeling M, Teljeur C, Feely J, Bennett K. Potentially inappropriate prescribing and cost outcomes for older people: a national population study. Br J Clin Pharmacol. 2010 Jan 28;69(5):543-52.

14. Krentz HB, Cosman I, Lee K, Ming JM, Gill MJ. Pill burden in HIV infection: 20 years of experience. Antivir Ther. 2012;17(5):833-40.

15. Inouye SK, Studenski S, Tinetti ME, Kuchel GA. Geriatric syndromes: clinical, research, and policy implications of a core geriatric concept. J Am Geriatr Soc. 2007 May;55(5):780-91.

16. Hajjar ER, Cafiero AC, Hanlon JT. Polypharmacy in elderly patients. Am J Geriatr 
Pharmacother. 2007 Dec;5(4):345-51.

17. Gleason L, Luque AE, Shah K. Polypharmacy in the HIV-infected older adult population. Clin Interv Aging. 2013;8:749-63.

18. Moore HN, Mao L, Oramasionwu CU. Factors associated with polypharmacy and the prescription of multiple medications among persons living with HIV (PLWH) compared to nonPLWH. AIDS Care. 2015 Dec 2;27(12):1443-8.

19. Marzolini C. Prevalence of comedications and effect of potential drug-drug interactions in the Swiss HIV Cohort Study. Antivir Ther. 2010;15:413-23.

20. Marzolini C, Back D, Weber R, Furrer H, Cavassini M, Calmy A, et al. Ageing with HIV: medication use and risk for potential drug-drug interactions. J Antimicrob Chemother. 2011 Sep 1;66(9):2107-11.

21. Holtzman C, Armon C, Tedaldi E, Chmiel JS, Buchacz K, Wood K, et al. Polypharmacy and Risk of Antiretroviral Drug Interactions Among the Aging HIV-Infected Population. J Gen Intern Med. 2013 Oct 20;28(10):1302-10.

22. Piscitelli SC, Gallicano KD. Interactions among Drugs for HIV and Opportunistic Infections. Wood AJJ, editor. N Engl J Med. 2001 Mar 29;344(13):984-96.

23. Huang L, Wring SA, Woolley JL, Brouwer KR, Serabjit-Singh C, Polli JW. Induction of PGlycoprotein and Cytochrome P450 3A by HIV Protease Inhibitors. Drug Metab Dispos. 2001;29(5).

24. Choo EF, Leake B, Wandel C, Imamura H, Wood AJJ, Wilkinson GR, et al. Pharmacological Inhibition of P-glycoprotein Transport Enhances the Distribution of HIV-1 Protease Inhibitors into Brain and Testes. Drug Metab Dispos. 2000;28(6).

25. Nguyen N, Holodniy M. HIV infection in the elderly. Clin Interv Aging. 2008;3(3):453-72.

26. Bagkeris E, Burgess L, Mallon PW, Post FA, Boffito M, Sachikonye M, et al. Cohort profile: The Pharmacokinetic and clinical Observations in PeoPle over fiftY (POPPY) study. Int J Epidemiol. 2018 Oct 1;47(5):1391-1392e.

27. UK Collaborative HIV Cohort Steering Committee. The creation of a large UK-based multicentre cohort of HIV-infected individuals: The UK Collaborative HIV Cohort (UK CHIC) Study. HIV Med. 2004 Mar;5(2):115-24.

28. Hovstadius B, Hovstadius K, Astrand B, Petersson G. Increasing polypharmacy - an individualbased study of the Swedish population 2005-2008. BMC Clin Pharmacol. 2010 Dec 2;10:16.

29. Masnoon N, Shakib S, Kalisch-Ellett L, Caughey GE. What is polypharmacy? A systematic review of definitions. BMC Geriatr. 2017 Dec 10;17(1):230.

30. Liverpool HIV Interactions [Internet]. [cited 2017 Sep 17]. Available from: http://www.hivdruginteractions.org/checker

31. Interactions | Clinical Drug Information [Internet]. [cited 2017 Sep 27]. Available from: http://www.wolterskluwercdi.com/lexicomp-online/user-guide/tools-interactions/

32. TILDA. Polypharmacy in adults over 50 in Ireland: Opportunities for cost saving and improved healthcare. 2012;

33. Schouten J, Wit FW, Stolte IG, Kootstra NA, van der Valk M, Geerlings SE, et al. Cross-sectional Comparison of the Prevalence of Age-Associated Comorbidities and Their Risk Factors 
Between HIV-Infected and Uninfected Individuals: The AGEhIV Cohort Study. Clin Infect Dis. 2014 Dec 15;59(12):1787-97.

34. Siefried KJ, Mao L, Cysique LA, Rule J, Giles ML, Smith DE, et al. Concomitant medication polypharmacy, interactions and imperfect adherence are common in Australian adults on suppressive antiretroviral therapy. AIDS. 2018 Jan 2;32(1):35-48.

35. Djatche L, Lee S, Singer D, Hegarty SE, Lombardi M, Maio V. How confident are physicians in deprescribing for the elderly and what barriers prevent deprescribing? J Clin Pharm Ther. 2018 Aug 1;43(4):550-5. 
Table 1: Characteristics of the study population

\begin{tabular}{|c|c|c|c|}
\hline & $\begin{array}{l}\text { PLWH aged } \geq 50 \\
\text { years }\end{array}$ & $\begin{array}{l}\text { PLWH aged }<50 \\
\text { years }\end{array}$ & $\begin{array}{l}\text { HIV-negative } \\
\text { controls aged } \geq 50 \\
\text { years }\end{array}$ \\
\hline $\mathbf{N}$ & 698 & 374 & 304 \\
\hline \multicolumn{4}{|l|}{ Age (years) } \\
\hline Median (Range) & $56(50-82)$ & $43(20-49)$ & $58(50-87)$ \\
\hline \multicolumn{4}{|l|}{ Gender, n (\%) } \\
\hline \multirow{2}{*}{$\begin{array}{l}\text { Male } \\
\text { Female }\end{array}$} & $612(87.7)$ & $302(80.8)$ & $195(64.1)$ \\
\hline & $86(12.3)$ & $72(19.3)$ & 109 (35.9) \\
\hline \multicolumn{4}{|l|}{ Race, n (\%) } \\
\hline \multirow{2}{*}{$\begin{array}{l}\text { White } \\
\text { Black African }\end{array}$} & 603 (86.3) & 299 (71.9) & $273(89.8)$ \\
\hline & $95(13.6)$ & $75(28.1)$ & $31(10.2)$ \\
\hline \multicolumn{4}{|l|}{ CD4 (cells/mm³) } \\
\hline & 680 & 376 & \\
\hline median (IQR) & $610(467,792)$ & $646(499,874)$ & $\mathrm{n} / \mathrm{a}$ \\
\hline (range) & $(58,2460)$ & $(10,2513)$ & \\
\hline \multicolumn{4}{|l|}{$\begin{array}{l}\text { Viral load } \\
\text { copies/mL }\end{array}$} \\
\hline$n=$ & 696 & 372 & \\
\hline median (IQR) & $40(40,50)$ & $40(39,50)$ & $\mathrm{n} / \mathrm{a}$ \\
\hline (range) & $(1,138175)$ & $(1,360000)$ & \\
\hline $\begin{array}{l}\mathrm{N}(\%) \text { taking ARV } \\
\text { medications }\end{array}$ & 689(98.7\%) & $355(94.9 \%)$ & $\mathrm{n} / \mathrm{a}$ \\
\hline N (\%) taking NRTI & $594(85.1 \%)$ & $334(89.3 \%)$ & $\mathrm{n} / \mathrm{a}$ \\
\hline $\mathbf{N}(\%)$ taking PI & $302(43.3 \%)$ & $139(37.2 \%)$ & $\mathrm{n} / \mathrm{a}$ \\
\hline N (\%) taking II & $101(14.5 \%)$ & $49(13.1 \%)$ & $\mathrm{n} / \mathrm{a}$ \\
\hline
\end{tabular}

IQR: Interquartile range, PLWH: People Living With HIV, n/a: Not Applicable NRTI: Nucleoside Reverse Transcriptase Inhibitor, PI: Protease Inhibitor, II: Integrase Inhibitor 
Table 2: Numbers of medications and interactions in the three groups

\begin{tabular}{|c|c|c|c|c|}
\hline & $\begin{array}{c}\mathrm{PLWH} \text { aged } \geq 50 \\
\text { years }\end{array}$ & $\begin{array}{c}\text { PLWH aged }<50 \\
\text { years }\end{array}$ & $\begin{array}{c}\text { HIV-negative } \\
\text { controls aged } \geq 50 \\
\text { years }\end{array}$ & p-value \\
\hline $\begin{array}{l}\text { Number of medications } \\
\text { Median (range) }\end{array}$ & $6(0-27)$ & $4(0-17)$ & $1(0-39)$ & 0.001 \\
\hline $\begin{array}{l}\text { Number of co- } \\
\text { medications (excluding } \\
\text { ARV medications in } \\
\text { HIV-positive groups) }\end{array}$ & & & & 0.001 \\
\hline 0 & $178(25.5 \%)$ & $142(38 \%)$ & 122 (40.1\%) & \\
\hline $1-4$ & $312(44.7 \%)$ & $179(47.9 \%)$ & $142(46.7 \%)$ & \\
\hline $5-9$ & $155(22.2 \%)$ & $49(13.1 \%)$ & $35(11.5 \%)$ & \\
\hline$\geq 10$ & $53(7.6 \%)$ & $4(1.1 \%)$ & $5(1.7 \%)$ & \\
\hline $\begin{array}{l}\text { Numbers of people with } \\
\text { polypharmacy } \\
\text { ( } \geq 5 \text { total medications) }\end{array}$ & $\begin{array}{c}459 \\
(65.8 \%)\end{array}$ & $\begin{array}{c}180 \\
(48.1 \%)\end{array}$ & $\begin{array}{c}40 \\
(13.2 \%)\end{array}$ & 0.001 \\
\hline $\begin{array}{l}\text { Numbers of people with } \\
\text { polypharmacy } \\
\text { ( } \geq 5 \text { medications) } \\
\text { excluding ARVs in } \\
\text { PLWH }\end{array}$ & $\begin{array}{c}208 \\
(29.8 \%)\end{array}$ & $\begin{array}{c}53 \\
(14.2 \%)\end{array}$ & $\mathrm{n} / \mathrm{a}$ & 0.001 \\
\hline $\begin{array}{l}\text { PDDI between non-ARV } \\
\text { drugs }\end{array}$ & & & & \\
\hline$N(\%) \geq 1$ & $252(36.1 \%)$ & $76(20.3 \%)$ & $50(16.4 \%)$ & 0.001 \\
\hline Median (range) & $0(0-48)$ & $0(0-21)$ & $0(0-14)$ & 0.001 \\
\hline \multicolumn{5}{|l|}{$\begin{array}{l}\text { PDDI between ARV and } \\
\text { non-ARV drugs }\end{array}$} \\
\hline$N(\%) \geq 1$ & $400(57.3 \%)$ & $121(32.4 \%)$ & - & 0.001 \\
\hline Median (range) & $1(0-11)$ & $0(0-5)$ & - & 0.001 \\
\hline
\end{tabular}

PLWH: People Living with HIV, ARV: Anti-retroviral, PDDI: potential clinically significant drug-drug interaction, n/a: not applicable 
Table 3: Non-ARV drugs involved in interactions with ARVs

\begin{tabular}{|c|c|c|c|}
\hline $\begin{array}{l}\text { PLWH } \geq 50 \\
\text { years }\end{array}$ & $\begin{array}{l}\text { Number of total } \\
\text { ARV/non-ARV } \\
\text { interactions (\%) }\end{array}$ & Examples of Interactions & Potential clinical consequence $^{30}$ \\
\hline $\begin{array}{l}\text { Total } \\
\text { number of } \\
\text { interactions }\end{array}$ & $913(100.0)$ & & \\
\hline $\begin{array}{l}\text { Lipid } \\
\text { lowering } \\
\text { drugs }\end{array}$ & $147(16.1)$ & $\begin{array}{l}\text { Darunavir/Ritonavir and } \\
\text { Atorvastatin }\end{array}$ & $\begin{array}{l}\text { Increased atorvastatin } \\
\text { concentrations. Atorvastatin should be } \\
\text { started at } 10 \mathrm{mg} \text { daily and maximum dose } \\
\text { should not exceed } 40 \mathrm{mg} \text { day. }\end{array}$ \\
\hline $\begin{array}{l}\text { Anti- } \\
\text { infectives } \\
\text { for systemic } \\
\text { use }\end{array}$ & $102(11.2)$ & $\begin{array}{l}\text { Lamivudine and } \\
\text { Trimethoprim/Sulfamethoxazole }\end{array}$ & $\begin{array}{l}\text { Increased lamivudine concentrations. Co- } \\
\text { administration of treatment doses of } \\
\text { trimethoprim/sulfamethoxazole should be } \\
\text { avoided. }\end{array}$ \\
\hline Opioids & $69(7.6)$ & Etravirine and Morphine & $\begin{array}{l}\text { Potential increase in morphine exposure. } \\
\text { Opioid toxicity should be monitored for. }\end{array}$ \\
\hline $\begin{array}{l}\text { Anti- } \\
\text { depressants }\end{array}$ & $67(7.3)$ & Atazanavir and Sertraline & $\begin{array}{l}\text { Potential increased sertraline exposure. } \\
\text { Sertraline dose should be titrated to } \\
\text { response. }\end{array}$ \\
\hline $\begin{array}{l}\text { Anti- } \\
\text { platelets }\end{array}$ & $58(6.4)$ & $\begin{array}{l}\text { Darunavir/Ritonavir and } \\
\text { Clopidogrel }\end{array}$ & $\begin{array}{l}\text { Decrease in active metabolite of } \\
\text { clopidogrel which leads to insufficient } \\
\text { inhibition of platelet aggregation. } \\
\text { Contraindicated. }\end{array}$ \\
\hline $\begin{array}{l}\text { PLWH }<50 \\
\text { years }\end{array}$ & $\begin{array}{l}\text { Number of total } \\
\text { ARV/non-ARV } \\
\text { interactions (\%) }\end{array}$ & & \\
\hline $\begin{array}{l}\text { Total } \\
\text { number of } \\
\text { interactions }\end{array}$ & $201(100.0)$ & & \\
\hline $\begin{array}{l}\text { Anti- } \\
\text { infectives } \\
\text { for systemic } \\
\text { use }\end{array}$ & 36 (17.9) & Etravirine and Fluconazole & $\begin{array}{l}\text { Increased Etravarine exposure. Limited } \\
\text { clinical date on effect of this. }\end{array}$ \\
\hline $\begin{array}{l}\text { Anti- } \\
\text { depressants }\end{array}$ & $22(10.9)$ & $\begin{array}{l}\text { Darunavir/Ritonavir/Efavirenz } \\
\text { and Citalopram }\end{array}$ & $\begin{array}{l}\text { Increased Citalopram exposure. } \\
\text { Monitoring may be necessary. }\end{array}$ \\
\hline $\begin{array}{l}\text { Lipid } \\
\text { lowering } \\
\text { drugs }\end{array}$ & $17(8.5)$ & Efavirenz and Atorvastatin & $\begin{array}{l}\text { Decreased Atorvastatin exposure. } \\
\text { Cholesterol should be monitored, and } \\
\text { dose of Atorvastatin may need to be } \\
\text { increased. }\end{array}$ \\
\hline Hypnotics & $16(8)$ & $\begin{array}{l}\text { Darunavir/Ritonavir and } \\
\text { Zolpidem }\end{array}$ & $\begin{array}{l}\text { Increased exposure to Zolpidem which } \\
\text { may increase sedation. }\end{array}$ \\
\hline Opioids & $15(7.5)$ & $\begin{array}{l}\text { Darunavir/Ritonavir and } \\
\text { Buprenorphine }\end{array}$ & $\begin{array}{l}\text { Potential increase in exposure to } \\
\text { metabolites of buprenorphine. Opioid } \\
\text { toxicity should be monitored for. }\end{array}$ \\
\hline
\end{tabular}


Table 4: Non-ARV Drug Interactions

\begin{tabular}{|c|c|c|c|c|}
\hline & $\begin{array}{l}\text { PLWH } \\
\text { aged } \geq 50 \\
\text { years }\end{array}$ & $\begin{array}{l}\text { PLWH aged } \\
<50 \text { years }\end{array}$ & $\begin{array}{l}\text { HIV-negative } \\
\text { controls aged } \geq 50 \\
\text { years }\end{array}$ & $\begin{array}{l}\text { Example of interaction in this } \\
\text { class and Clinical Effect }\end{array}$ \\
\hline $\begin{array}{l}\text { Total non-ARV } \\
\text { non-ARV PDDI }\end{array}$ & 1185 & 240 & 136 & \\
\hline $\begin{array}{l}\text { Avoid } \\
\text { Combination } n \\
\text { (\%) }\end{array}$ & $\begin{array}{l}31 \\
(2.6 \%)\end{array}$ & $1(0.4 \%)$ & $1(0.7 \%)$ & $\begin{array}{l}\text { Domperidone and Ciprofloxacin. } \\
\text { Co-administration can cause QTC } \\
\text { prolongation. }\end{array}$ \\
\hline $\begin{array}{l}\text { Modify Therapy } \\
\text { n (\%) }\end{array}$ & $\begin{array}{l}190 \\
(16 \%)\end{array}$ & $41(17.1 \%)$ & $23(16.9 \%)$ & $\begin{array}{l}\text { Simvastatin and Amlodipine. } \\
\text { Amlodipine increases exposure } \\
\text { to simvastatin. Doses of } \\
\text { simvastatin should be capped at } \\
20 \mathrm{mg} \text {. }\end{array}$ \\
\hline $\begin{array}{l}\text { Separate } \\
\text { Administration } \\
\mathrm{n}(\%)\end{array}$ & $\begin{array}{l}34 \\
(2.9 \%)\end{array}$ & $7(2.9 \%)$ & $2(1.5 \%)$ & $\begin{array}{l}\text { Doxycycline and Calcium. The } \\
\text { absorption of doxycycline may be } \\
\text { impaired by concurrently } \\
\text { administered calcium. } \\
\text { Administration should be } \\
\text { separated. }\end{array}$ \\
\hline Monitor & $\begin{array}{l}741 \\
(62.5 \%)\end{array}$ & $142(59.2 \%)$ & $78(57.4 \%)$ & $\begin{array}{l}\text { Zolpidem and Citalopram. } \\
\text { Increased risk of psychomotor } \\
\text { impairment when these are co- } \\
\text { administered. }\end{array}$ \\
\hline No Action & $\begin{array}{l}189 \\
(15.9 \%)\end{array}$ & $49(20.4 \%)$ & $32(23.5 \%)$ & $\begin{array}{l}\text { Aspirin and Ascorbic Acid. } \\
\text { Aspirin may decrease the serum } \\
\text { concentration of Ascorbic Acid. }\end{array}$ \\
\hline
\end{tabular}

PDDI: Potential Drug -Drug Interaction 
Table 5: Association of PDDI between non-ARV and non-ARV drugs and PDDI between ARV and non$A R V$ drugs with HIV group, gender, race and ARV therapy.

\begin{tabular}{|c|c|c|c|c|}
\hline & \multicolumn{2}{|c|}{$\begin{array}{l}\text { PDDI between non-ARV and } \\
\text { non-ARV drugs }\end{array}$} & \multicolumn{2}{|c|}{$\begin{array}{l}\text { PDDI between ARV and non-ARV } \\
\text { drugs }\end{array}$} \\
\hline & $\mathrm{OR}(95 \% \mathrm{Cl})$ & $p$-value* & OR $(95 \% \mathrm{Cl})$ & p-value* \\
\hline \multicolumn{5}{|l|}{ HIV group } \\
\hline HIV-negative & Ref. & & - & - \\
\hline PLWH aged $<50$ years & $1.37(0.91,2.06)$ & 0.13 & Ref. & \\
\hline PLWH aged $\geq 50$ years & $3.08(2.16,4.42)$ & $<0.001$ & $2.65(2.02,3.47)$ & $<0.001$ \\
\hline \multicolumn{5}{|l|}{ Gender } \\
\hline Female & Ref. & & Ref. & \\
\hline Male & $0.82(0.56,1.20)$ & 0.31 & $0.75(0.47,1.21)$ & 0.24 \\
\hline \multicolumn{5}{|l|}{ Race } \\
\hline Black African & Ref. & & Ref. & \\
\hline White & $0.98(0.65,1.47)$ & 0.92 & $2.00(1.26,3.18)$ & 0.003 \\
\hline \multicolumn{5}{|l|}{ Current cART } \\
\hline Any PI & - & & Ref. & \\
\hline Any NNRTI without a PI & - & & $0.53(0.41,0.69)$ & $<0.001$ \\
\hline Any II without a PI/NNRTI & - & & $0.46(0.28,0.73)$ & 0.001 \\
\hline Others & - & & $0.10(0.04,0.26)$ & $<0.001$ \\
\hline
\end{tabular}

${ }^{*} p$-values obtained from multivariable logistic regression models.

PDDI: Potential Drug-Drug Interaction, ARV: Anti-retroviral, HIV: Human Immunodeficiency Virus, PLWH: People Living With HIV, OR: Odds Ratio, Cl: Confidence Interval PI: Protease Inhibitor, NNRTI: Non-Nucleoside Reverse Transcriptase Inhibitor, II: Integrase Inhibitor 